\title{
The simulation of indoor daylight glare based on the location
}

DOI: 10.36909/jer.12177

Xin Liu, Qiguang Deng, Shuo Wei, Linlin Meng, Guanying Cao*

Research Institute of Photonics, Dalian Polytechnic University, Dalian, 116034, China

*Email: gycao@dlpu.edu.cn; Corresponding Author.

\begin{abstract}
Because well-being and energy efficiency are both important issues in building, there is an increase need for comfort and energy saving. Some critical factors affecting them are still not clear. This paper firstly investigated the influence of the orientation of the window on indoor daylight glare. Secondly, the influence of longitude and latitude on indoor daylight glare, and the distribution of daylight glare in China by using K-Nearest Neighbor algorithm (KNN algorithm) were studied. Daylight Glare Probability (DGP) was used as glare evaluation index in the study. The results show that daylight glare is the most serious in the west and south, then in the east and the least in the north for the window of the room in different orientations. The glare gradually increases with the increase of the latitude of the cities at the same longitude. The effect of the longitude of the cities at the same latitude on glare has no specific linear relationship. We also get the glare situation of cities without meteorological files by investigating the distribution of daylight glare in China.

Key words: Daylight Glare Probability (DGP); K-Nearest Neighbor algorithm (KNN algorithm); orientation of window; latitude and longitude of cities; distribution of daylight glare.
\end{abstract}




\section{INTRODUCTION}

Energy saving and well-being are two important issues in construction. Using daylight can not only reduce the energy consumption of electric lighting, but also provide people with a comfortable environment. With the proposal of Climate-Based-Daylight Modeling (CBDM), dynamic simulation based on regional light climate has become the main trend of lighting research. For static, small artificial lighting system, there are many evaluation indicators, such as BRS glare equation (BGI), CIE glare index (CGI), and Unified Glare Rating (UGR) (Petherbridge et al., 1950, Einhorn, 1969, Einhorn, 1979 \& CIE, 1992). For dynamic, large daylight glare sources, the evaluation index is Daylight glare index (DGI) (Hopkinson, 1972, Chauvel et al., 1982). In order to judge the accuracy of the glare index, Wienold and Christoffersen (2006) used CCD cameras to evaluate daylight environment and found that there were a squared correlation factor of 0.56 for the DGI. They developed a new discomfort glare index for daylight, which is called Daylight Glare Probability (DGP).There was a very strong correlation (squared correlation of 0.94 ) between DGP and the user's response regarding perception. Wienold (2009) also studied three different methods based on DGP to evaluate the dynamic daylight glare, which were timestep by timestep calculation, simplified daylight glare probability DGPs and enhanced simplified DGP calculation eDGPs. The eDGPs method was validated against two hour-by-hour full year datasets by using a fabric and a venetian blinds shading system. Reinhart et al. (Reinhart et al., 2001, Christoph et al., 2002, Reinhart et al., 2003, Reinhart, 2004 \& Reinhart, 2006) compared DGI, CGI Visual Comfort Probability (VCP), UGR and DGP and found that DGP was the most accurate, they also introduced 'adaptive zone' which building occupants may freely adjust their position and view in order to minimise the effect of glare. All the above studies fully prove the rationality and accuracy of DGP in evaluating natural glare, so DGP is selected as the evaluation index of daylight glare. With the development of computers, it is possible to calculate the value of DGP, and the accuracy of the calculated value of DGP needs to be verified. 
Suk et al. (Suk et al., 2012, Suk et al., 2017) investigated Evalglare software, DGP and high dynamic range imaging for daylight glare analysis and they found that HDR and Evalglare can be used to document and evaluate various discomfort glare scenes DGP calculation in Evalglare can be more reliable. There are many factors influencing discomfort glare perception. Van Den Wymelenberg et al. (2015) found that luminance-based metrics were more capable than illuminance-based metrics for fitting the range of subjective responses. Bullough (2009) found that glare sources with a large number of short wavelengths resulted in higher perceived discomfort glare. Sharma, L et al. (2018) evaluated the impact of passive design measures to estimate the shading control for visual comfort. A review (Pierson et al., 2017, Pierson et al., 2018) on the factors influencing discomfort glare perception from daylight was published. Wang Qi et al. (2017) used Fresnel reflection theory and vector decomposition method and derived a polarization factor related to the glare intensity distribution and verified that the factor plays a leading role in eliminating glare. It is particularly important to understand the factors affecting glare and to take reasonable shading measures to reduce the impact of glare on the visual comfort of indoor personnel.

In this paper, the effects of the orientation of the window in room, the latitude and longitude of the cities on daylight glare and the distribution of daylight glare in China were studied by simulating the indoor daylight environment and using DGP as the evaluation index of daylight glare. These will have a certain value for reference to analyze the daylight glare in building.

\section{DAYLIGHT GLARE PROBABILITY (DGP)}

Daylight Glare Probability (DGP) was developed by Wienold and Christoffersen to evaluate the daylight glare, and it is a function of vertical eye illuminance, glare source luminance, solid angle and position index. DGP shows a very strong correlation (the square correlation factor is 0.94 ) with the user's perception of glare (Wienold et al., 2006). The Equation (1) for calculating DGP is as follows:

$$
\mathrm{DGP}=5.87 * 10-5 \mathrm{E}_{\mathrm{v}}+9.18 * 10-2 \log 10\left(1+\sum_{\mathrm{i}=1}^{\mathrm{n}} \frac{\mathrm{L}_{\mathrm{s}, \mathrm{i}}^{2} * \omega_{\mathrm{i}}}{\mathrm{E}_{v}^{1.87} * \mathrm{P}_{\mathrm{i}}^{2}}\right)+0.16
$$


Where $E_{v}$ is the vertical eye illuminance (lux); $L_{s, i}$ is the luminance of the glare source $\left(\mathrm{cd} / \mathrm{m}^{2}\right) ; \omega_{i}$ is the solid angle of the glare source (sr); and $P_{i}$ is the position index relative to the glare source. DGP is divided into four levels, as shown in Table 1.

Table1 DGP levels

\begin{tabular}{|c|c|c|c|c|}
\hline Level & First level & Second level & Third level & Fourth level \\
\hline glare perception & imperceptible & perceptible & disturbing & intolerable \\
\hline range & $0-0.35$ & $0.35-0.4$ & $0.4-0.45$ & $0.45-1$ \\
\hline
\end{tabular}

\section{METEOROLOGICAL FILES}

A meteorological file is a collection of meteorological data that is produced by measuring the temperature, humidity, hours of sunshine, wind speed, cloud cover, radiation, and air pressure of an area. There are many data formats and types of meteorological files (Hall et al., 1978, Davies et al., 1989, Zhang et al., 2004). In our previous research, the effects of meteorological file such as Chinese Typical Year Weather (CTYW), Chinese Standard Weather Data (C) (CSWD (C)), Chinese Standard Weather Data (A) (CSWD (A)), International Weather for Energy Calculation (IWEC) and Meteonorm on daylight glare were studied in Beijing, Shanghai and Guangzhou of China. The results show that CSWD (C) and CTYW should be used when we study the time distribution law of DGP. It is recommended to use CSWD (C), CTYW, and Meteonorm when we study the total distribution of DGP (Deng et al., 2016). Therefore, China standard weather data (CSWD(C)) was selected to study the effect of the orientation of the window in room, the latitude and longitude of the cities on indoor daylight glare and the distribution of daylight glare of China in the paper. CSWD (C) was compiled from the data of 270 meteorological stations measured by Dr. Jiang Yi from the Department of Building Science and Technology of Tsinghua University and the China Meteorological Bureau (China Meteorological Bureau, 2005). 


\section{DIVA FOR RHINO}

DIVA is a plug-in for Rhino. It was originally developed by Harvard Design Institute and further developed by Solemma, which can analyze a building's thermal radiation, rendering, glare on a given day, and total glare throughout the year. First using the Rhino software to build a 3D model, then importing the meteorological file into DIVA, and the daylight glare will be calculated according to a CIE sky model (National Standarization Technical Committee, 2006) and the position and distribution of the sun in the sky.

\section{K-NEAREST NEIGHBOR ALGORITHM (KNN ALGORITHM)}

The algorithm principle of general classification is simply to record the corresponding categories of all labeled data, and then compare the data of test objects with labeled data each time. If the data of the test object and the data of a training object exactly match, the classification of the test object can be found. But this rarely happens in practice. More often, a test object will be matched to multiple training objects, resulting in a training object being divided into multiple classes. In order to solve these problems, K-Nearest Neighbor algorithm (KNN algorithm) came into being (Larose et al., 2005). KNN algorithm replaces the matching problem between objects by calculating the distance between objects and taking the distance as the similarity index between each object. Euclidean distance is generally used in the KNN algorithm. The Equation (2) for calculating Euclidean distance is as follows:

$$
\mathrm{d}(\mathrm{x}, \mathrm{y})=\sqrt{\sum_{\mathrm{i}=1}^{\mathrm{n}}\left(\mathrm{x}_{\mathrm{i}}-\mathrm{y}_{\mathrm{i}}\right)^{2}}
$$

At the same time, it should be noted that KNN makes decisions according to the dominant category among k objects, rather than a single object category decision. The idea of KNN algorithm is that in the case of annotated data, by comparing the features of test data with those of annotated data, the first $\mathrm{k}$ data that are most similar to them can be found. Then, the category corresponding to the test data is the one that appears most frequently in the $\mathrm{k}$ data. 


\section{THE SELECTION OF THE LOCATION}

When we studied the effect of the orientation of the window in room on daylight glare, we chose one room in Beijing. The window of the room faces east, south, west and north, respectively. We chose a latitude and a longitude through Beijing $\left(\mathrm{N} 39^{\circ}, \mathrm{E} 116^{\circ}\right)$ shown in Figure 1 for studying the effect of location of the cities, including $\mathrm{N} 23^{\circ}$ of Shantou, N30 of Wuhan, $\mathrm{N} 36^{\circ}$ of Jinan, N39 of Beijing and $\mathrm{N} 48^{\circ}$ of Hailar as the research subjects for investigating the effect of the latitude of the cities and $\mathrm{E} 97^{\circ}$ of Yumen, E105 ${ }^{\circ}$ of Bayan, E110 of Yulin, E116 of Beijing and E121 ${ }^{\circ}$ of Dalian as the research subjects for investigating the effect of the longitude of the cities. For the accuracy of the study, we chose another latitude at $\mathrm{N} 30^{\circ}$ that is through E91 ${ }^{\circ}$ of Lasa, E104 ${ }^{\circ}$ of Chengdu, E109 of Enshi, E116 ${ }^{\circ}$ of Wuhan and $\mathrm{E} 120^{\circ}$ of Hangzhou.

In order to verify the effect of latitude and longitude of cities on daylight glare and to get the glare situation of cities without meteorological files, we also studied the distribution of daylight glare throughout China. In the process of selecting cities in this study, it is considered that almost every provincial capital has meteorological file, while other cities in the province may not have meteorological file. At the same time considering the selected cities need to cover as much as possible between the provinces throughout the country and to ensure that every city has some of the difference of the latitude and longitude, so we chose Beijing, Changchun, Changsha, Chongqing, Dalian, Fuzhou, Guangzhou, Guiyang, Nanning, Hefei, Jinan, Harbin, Kunming, Lanzhou, Nanchang, Nanjing, Shanghai, Shenyang, Shijiazhuang, Taiyuan, Tianjin, Wuhan, xi' an, Xining, Yinchuan, Zhengzhou this 26 cities to study. All the windows face south in this study.

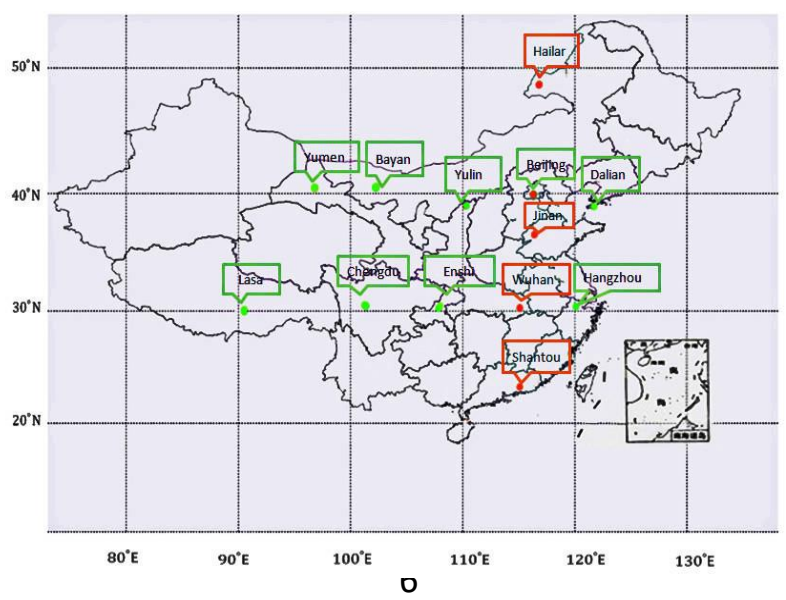


Figure 1 The places for research

\section{SIMULATION MODEL}

A room model should be built for investigating the daylight glare for the orientation of the window, different latitude and longitude of the cities and the distribution of daylight glare in China. In the paper, the length and width of the room are $4.00 \mathrm{~m}$, the height is $2.80 \mathrm{~m}$. The length of the window is $3.00 \mathrm{~m}$, and the height is $1.40 \mathrm{~m}$ in the model. The east, south, west and north walls of the model were built into a square to prevent the influence of wall-window ratio on the research results. Fig. 2 (a) is a front view, Fig. 2 (b) is a top view, Fig. 2 (c) is a left side view, and Fig. 2 (d) is a perspective view. The reflectance of the floor is $20 \%$, the reflectance of wall is $50 \%$, the reflectance of furniture is $50 \%$, the transmittance of glass is $65 \%$, the reflectance of roof is $10 \%$. Figure 3 shows the perspective of the simulation. The distance between the view position and facade is $1.40 \mathrm{~m}$ at $1.20 \mathrm{~m}$ height.

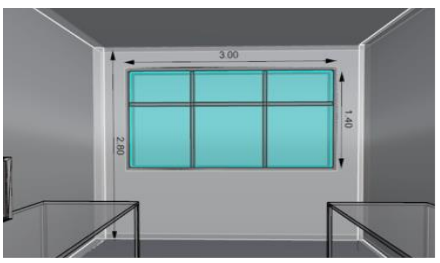

(a) front view

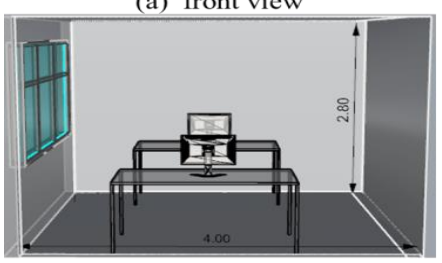

(c) left view

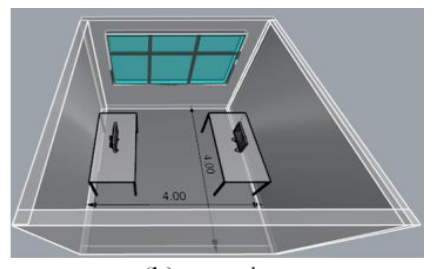

(b) top view

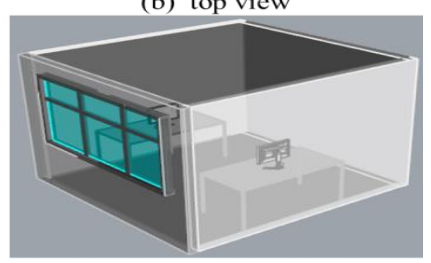

(d) perspective view

Figure 2 Simulation model (a) front view (b) top view (c) left view (d) perspective view

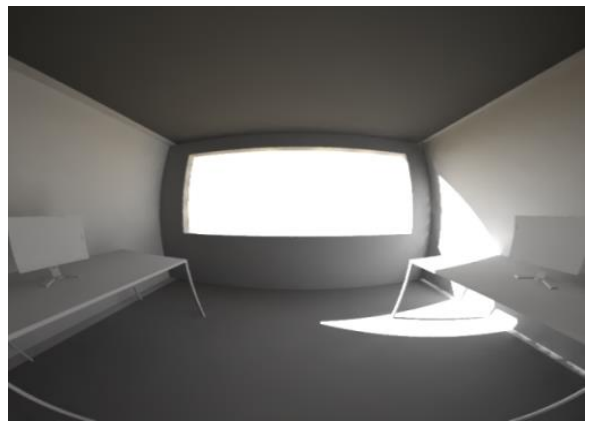

Figure 3 The perspective of the simulation by $180 \mathrm{deg}$. Fisheye 


\section{THE ORIENTATION OF THE WINDOW}

We chose a room in Beijing as the research subjects when we studied the effect of the orientation of the window in room on daylight glare. The meteorological file of Beijing was imported into DIVA for simulated analysis. Fig. 4(a) represents the distribution of annual daylight glare amount and Fig. 4(b) represents the histogram distribution of annual daylight glare when the window faces in north, east, south and west, respectively. The DGP was divided into four levels.

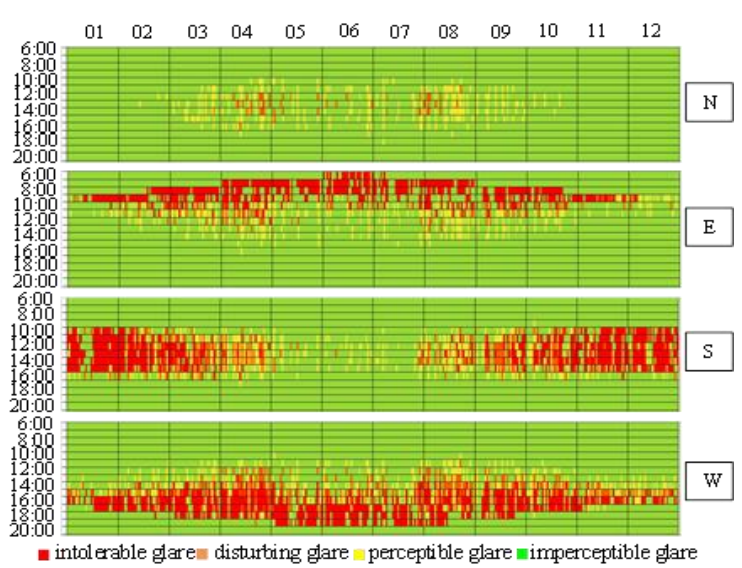

(a)

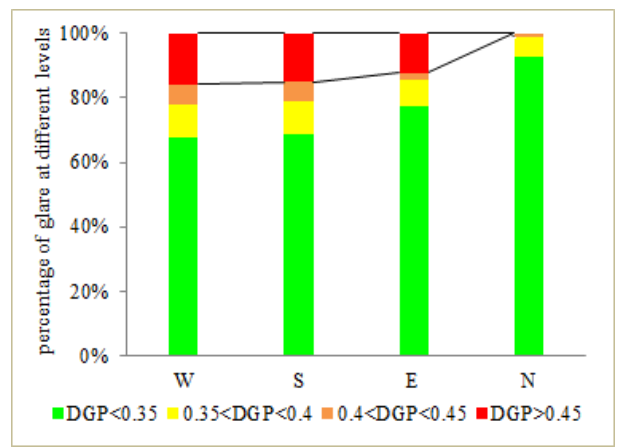

(b)

Figure 4 Annual daylight glare in different orientations of window

It can be seen from Fig. 4 (a) that the northern glare is the least, the glare is more serious in east between 7:00 AM to 10:00 AM, the southern glare is more serious in winter and less in summer, and the glare is more serious in west from 2:00 PM to 6:00 PM. The sun rises in the east and sets in the west, and as the time changes, the sun's elevation angle changes every moment. When the window faces south, the sunlight is long all day, so the glare is serious. When the window faces west, the light in the afternoon is intense. Therefore, the glare is more serious. The light is strong in the morning when the window faces east, but not as intense in the afternoon when the window faces west. Thus, the glare of the window in the east will be less than that when the window is in the south and the west. When the window faces north, there is no direct sunlight. It can be seen more intuitively that daylight glare in Beijing is the most serious in the west and south, then in the east and the least in the north from Fig. 4(b). 


\section{DIFFERENT LATITUDES}

The meteorological documents of Shantou $\left(\mathrm{N} 23^{\circ}\right)$, Wuhan $\left(\mathrm{N} 30^{\circ}\right)$, Jinan $\left(\mathrm{N} 36^{\circ}\right)$, Beijing $\left(\mathrm{N} 39^{\circ}\right)$, Hailar $\left(\mathrm{N} 48^{\circ}\right)$ were imported into DIVA for Rhino and calculated DGP of the model in Fig. 2, respectively. The distribution of annual daylight glare amount is shown in Fig. 5(a). Fig. 5(b) shows the histogram distribution of annual daylight glare at $\mathrm{E} 116^{\circ}$.

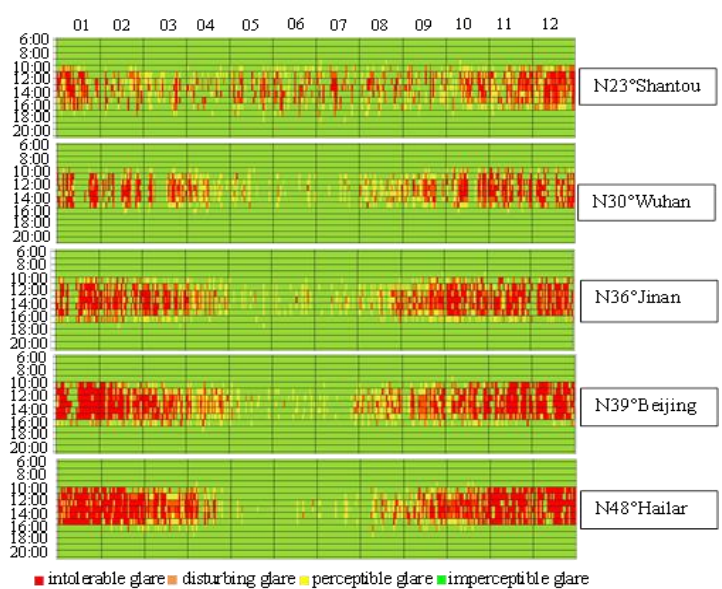

(a)

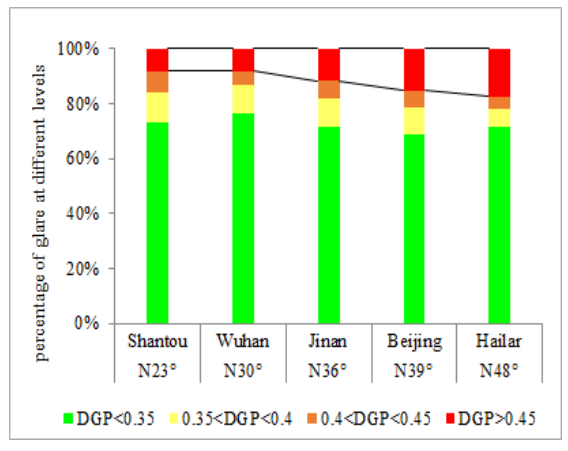

(b)

Figure 5 Annual daylight glare at E116

Fig. 5(a) and (b) show that the glare is the most serious in Hailar with the latitude of $\mathrm{N} 48^{\circ}$ where the intolerable glare (DGP > 0.45) is the most and there is the least glare in Shantou at $\mathrm{N} 23^{\circ}$ where the intolerable glare is the least. This is because the daily light rate gradually increases and cloud cover gradually decreases from south to north. The cloud shape is dominated by low clouds in the south and high and medium clouds in the north, which leads to direct sunlight in the north and diffuse light in the south. From Shantou, Wuhan, Jinan and Beijing to Hailar, the cloud cover decreases from south to north, direct sunlight increases, and natural light diffuses less. Because the illumination generated by direct sunlight is far greater than that generated by natural light diffuses, glare gradually increases with the increase of latitude. In addition, Shantou and Wuhan belong to low latitudes $\left(0^{\circ} \sim 30^{\circ}\right)$ with rainy weather and shorter sunshine hours, so the glare is not serious. Jinan, Beijing, and Hailar belong to the mid-latitude $\left(30^{\circ} \sim 60^{\circ}\right)$ area. They are rarely affected by the rainy weather and have longer sunshine 
time. Therefore, it is concluded that with the increase of latitude of the cities at the same longitude, the glare becomes more and more serious.

\section{DIFFERENT LONGITUDES}

The meteorological files of Yumen $\left(\mathrm{E} 97^{\circ}\right)$, Bayan $\left(\mathrm{E} 105^{\circ}\right)$, Yulin $\left(\mathrm{E} 110^{\circ}\right)$, Beijing $\left(\mathrm{E} 116^{\circ}\right)$ and Dalian $\left(\mathrm{E} 121^{\circ}\right)$ at $\mathrm{N} 39^{\circ}$ were imported into DIVA for Rhino and calculated DGP, respectively. Figure 6 shows the histogram distribution of annual daylight glare at $\mathrm{N} 39^{\circ}$.

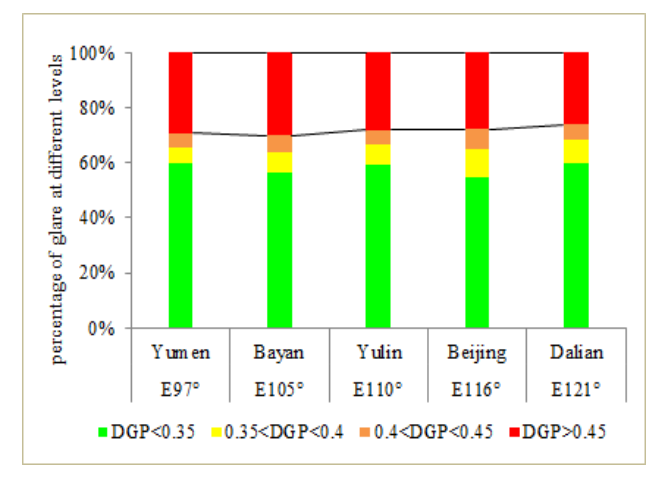

Figure 6 Histogram distribution of annual daylight glare at N39

We can see that the overall effect of longitude on the daylight glare in these five regions is not obvious. Among them, Yumen and Bayan have almost the same intolerable glare, Beijing has less intolerable glare than Yulin, and Dalian has the least glare. Yumen and Bayan are mostly a mountainous area with high terrain and have sufficient light. The high terrain reduces the light propagation distance and reduces the light intensity lost in the atmosphere. Thus, the glare in Yumen and Bayan is serious. While the terrain is flat in Yulin, and the perennial sand is relatively large, which scatters more light and reduces glare generated by direct light. We can see that the overall effect of longitude on the daylight glare in these five regions is not obvious. Among them, Yumen and Bayan have almost the same intolerable glare, Beijing has less intolerable glare than Yulin, and Dalian has the least glare. Yumen and Bayan are mostly a mountainous area with high terrain and have sufficient light. The high terrain reduces the light propagation distance and reduces the light intensity lost in the atmosphere. Thus, the glare in Yumen and Bayan is serious. While the terrain is flat in Yulin, and the perennial sand is relatively large, which scatters more light and reduces glare generated by direct light. 
Therefore, glare in Yulin area is less. The terrain in Beijing is flat and the annual sunshine percentage is less than Yulin, so the glare is less than that in Yulin. Dalian is close to the sea, and the light from the land is usually greater than that from the sea. Therefore, the light from Dalian is slightly less than that from places like Yumen, Bayan, Yulin and Beijing, so is the glare in Dalian. Table 2 shows the meteorological data and topography of these five regions at $\mathrm{N} 39^{\circ}$.

Table 2 Meteorological data and topography of these five regions at N39

\begin{tabular}{|c|c|c|c|c|c|}
\hline & Yumen & Bayan & Yulin & Beijing & Dalian \\
\hline topographic features & high terrain & high terrain & flat & flat & coastal \\
\hline sunshine (\%) & 80 & 80 & 70 & 60 & 60 \\
\hline precipitation (mm) & $<300$ & $<300$ & 300 & 300 & 300 \\
\hline cloud cover (\%) & 40 & 30 & 40 & 40 & 40 \\
\hline
\end{tabular}

Therefore, it is concluded that the effect of the longitude of the cities with the same latitude on daylight glare has no specific linear relationship by the analysis of Yumen, Bayan, Yulin, Beijing and Dalian. For the accuracy of the study, we chose latitude at $\mathrm{N} 30^{\circ}$ for our further study. Five regions including Lasa $\left(\mathrm{E} 91^{\circ}\right)$, Chengdu $\left(\mathrm{E} 104^{\circ}\right)$, Enshi $\left(\mathrm{E} 109^{\circ}\right)$, Wuhan $\left(\mathrm{E} 116^{\circ}\right)$ and Hangzhou $\left(\mathrm{E} 120^{\circ}\right)$ and Hangzhou $\left(\mathrm{E} 120^{\circ}\right)$ were selected. The histogram distribution of annual daylight glare at N30 ${ }^{\circ}$ is shown in Figure 7.

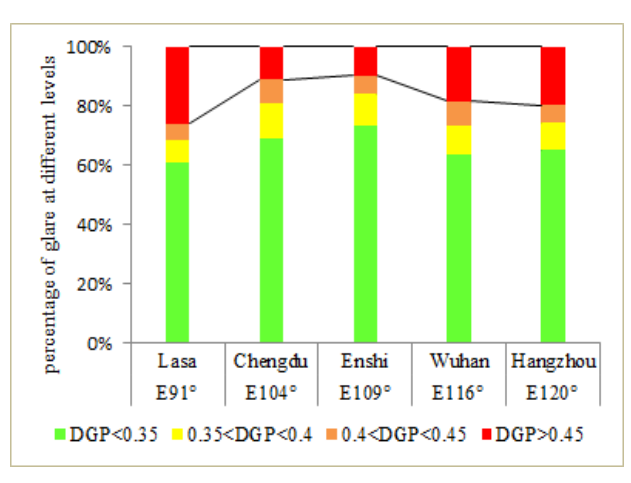

Figure 7 Histogram distribution of annual daylight glare at $\mathrm{N} 30^{\circ}$

It can also see that the effect of the longitude of the cities with the same latitude on daylight glare has no specific linear relationship. Lasa is not only sunny all year round, with little rain and long sunshine time, but also one of the cities with the highest altitude in the world. High altitude leads to less 
light distance and less light loss, so more light is received. In Chengdu and Enshi, there are many clouds, short sunshine time and moist air, which leads to less glare. While in Wuhan and Hangzhou, there is plenty of sunshine and little cloud cover. Thus, the glare increases compared with that in Chengdu and Enshi. Table 3 shows the meteorological data and topography of these five regions at $\mathrm{N} 30^{\circ}$.

Table 3 Meteorological data and topography of these five regions at N30

\begin{tabular}{|c|c|c|c|c|c|}
\hline & Lasa & Chengdu & Enshi & Wuhan & Hangzhou \\
\hline topographic features & high terrain & basin & mountain & flat hill & hill \\
\hline sunshine (\%) & 80 & 20 & 20 & 40 & 50 \\
\hline precipitation (mm) & 300 & 900 & 1500 & 1500 & 1500 \\
\hline cloud cover (\%) & 40 & 90 & 80 & 60 & 60 \\
\hline
\end{tabular}

Due to the differences of sea and land distribution, topography and weather conditions, the light intensity received at different longitudes is different. It is still concluded that the effect of the longitude of the cities with the same latitude on daylight glare has no specific linear relationship.

\section{DISTRIBUTION OF DAYLIGHT GLARE}

We also studied the distribution of daylight glare throughout China to verify the accuracy of the above experimental conclusion on the influence of latitude and longitude of cities on glare and to get the glare situation of cities without meteorological files. The meteorological files of these 26 cities were imported into DIVA for Rhino for annual total daylight glare analysis, and DGP was obtained, respectively. According to the DGP values of 26 cities, assuming that the ratio of glare (DGP > 0.35) to the total glare of the city is $\mathrm{N}$, and 26 cities are classified according to the ratio $\mathrm{N}$. The classification is as follows: the first grade is mild, with the proportion $\mathrm{N}$ less than $25 \%$; the second grade is moderate, with the proportion between $25 \%$ and $30 \%$. The third grade is serious, with the proportion between $30 \%$ and $37 \%$. The fourth grade is severe, with the proportion of $\mathrm{N}$ between $37 \%$ and $50 \%$. The proportion $\mathrm{N}$ of 26 cities is visualized and the glare level of each city is marked on the map. As shown in Figure 8. By inputting the data of longitude and latitude of all cities into KNN algorithm, the selection parameter 
$\mathrm{k}$ is equal to 4 as the number of grades, and the Euclidean distance is used to measure the similarity between each data point. Then, KNN algorithm can be applied to all data points to obtain the total daylight glare level of all longitude and latitude data points in China. Finally, all data points are visualized, as shown in Figure 9.

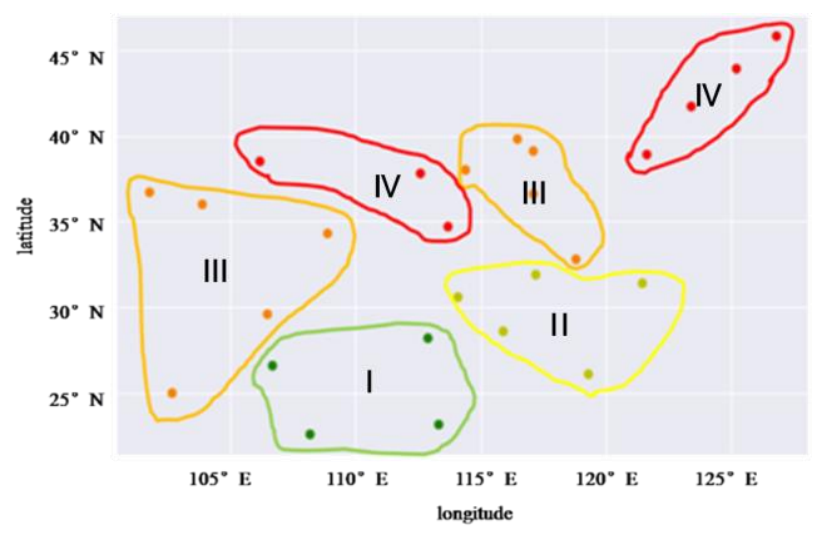

Figure 8 Longitude and latitude analysis chart of daylight glare level of 26 cities

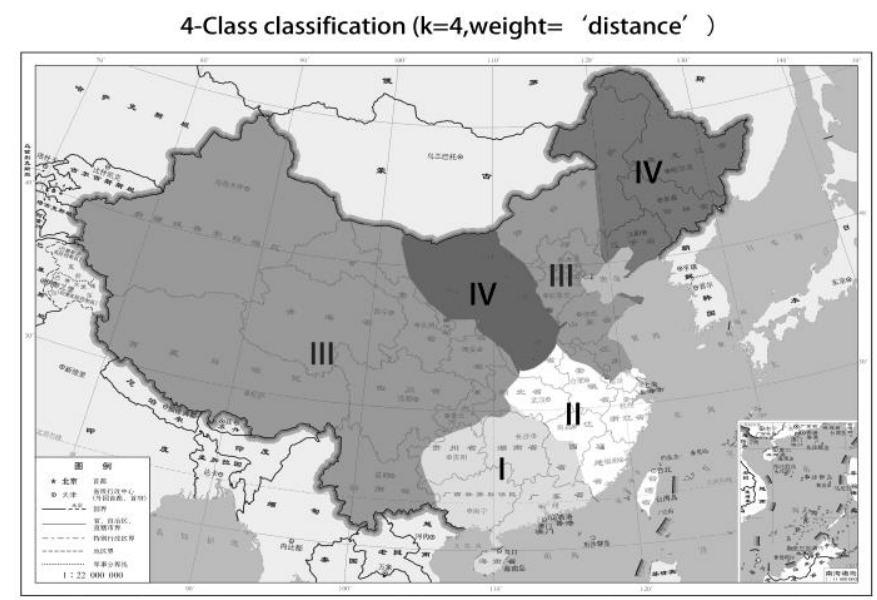

Figure 9 The distribution of daylight glare in China

Figure 8 and Figure 9 shows that daylight glare level in southeast China is generally at a low level, mainly in the first level and the second level, in which south China is basically at the first level. The middle region is mainly composed of the second and third levels, with Shanghai as the dividing line. The north of Shanghai is mainly composed of the third level, and the south of Shanghai is mainly composed of the second level. Northwest and southwest areas are basically based on the third level, and the fourth level is the place where the northwest and the north are bordered. The northern region is mainly the fourth, except Beijing and its surrounding areas as the third. In general, the daylight glare 
level in inland areas of China is relatively high, while that in southern coastal area of China is relatively low. This is because the cloud cover in China decreases as latitude increases from south to north, and the cloud is low in the south, and in the north is the middle and high clouds, causing the sun to scatter light in the south and direct light in the north. In addition, it is rainy in the south and sunny in the north, resulting the sunshine time in the north is longer than that in the south. Therefore, with the increase of latitude, glare gradually increases. Due to the differences of sea and land distribution, topography and weather conditions, the glare at different longitudes is different. Therefore, it is concluded that with the increase of latitude of the cities at the same longitude, the glare becomes more and more serious, the effect of the longitude of the cities with the same latitude on daylight glare has no specific linear relationship. The distribution of daylight glare in China is that the glare is less in the south of China and serious in the north of China.

\section{CONCLUSION}

This paper firstly studied the orientation of the window in room on daylight glare. The results show that daylight glare is the most serious in the west and south, then in the east and the least in the north by studying the window in different orientations in Beijing. When the window faces west, the light is strong in the afternoon; when the window faces south, the sunshine time is long; when the window faces east, the light is strong in the morning, but weaker than when the window faces west; when the window faces north, there is no direct sunlight. Therefore, if the windows facing east and west, we can use venetian blind system in the morning and afternoon to prevent excessive sunlight from entering the room. The window in the south can take shading measures according to the situation. If the people live in high-rise apartments, they can choose the windows of the room facing south or west. People who hate severe glare can live in rooms with windows facing north. For those who want plenty of sunlight and less glare, it's a wise idea to consider the room's windows facing east.

Then we studied the effects of the latitude and longitude of the cities on daylight glare and the distribution of daylight glare in China. The results show that the latitude of the cities with the same 
longitude has a positive correlation with the daylight glare by analyzing Shantou, Wuhan, Jinan, Beijing and Hailar at E116 ${ }^{\circ}$ With the increase of the latitude of the cities at the same longitude, the glare gradually increases. The effect of latitude on glare is mainly affected by cloud cover. Due to the characteristics of phosgene in China, the cloud cover gradually decreases from south to north, which leads to the diffusion of natural light in the south and the direct sunlight in the north. The effect of the longitude of the cities at the same latitude on daylight glare has no specific linear relationship by investigating Yumen, Bayan, Yulin, Beijing, Dalian at N39, and Lasa, Chengdu, Enshi, Wuhan, Hangzhou at $\mathrm{N} 30^{\circ}$, respectively. The effect of longitude on glare is affected by sunshine time, sea and land distribution, topography and weather conditions and so on. From the distribution of daylight glare in China, we can also see that glare increases gradually with the increase of latitude, longitude has no linear relationship to glare and get the glare situation of a cities without meteorological files. Therefore, some shading measures should be taken in high latitude areas to reduce the impact of daylight glare. These will play a guiding role in natural lighting design and be also useful for our choice of residential space by evaluating the impact of location on daylight glare.

\section{ACKNOWLEDGEMENTS}

This work was funded by the Natural Science Foundation of Liaoning Province, China (20180550017). We would like to thank Jan Wienold for his contribution to the evaluation of daylight glare and thank Solemma for providing us with the DIVA for Rhino license.

\section{REFERENCES}

Petherbridge, P., \& Hopkinson, R.G. 1950. Discomfort Glare and the Lighting of Buildings. Lighting Research and Technology 15(2): 39-79.

Einhorn, H.D. 1969. A new method for the assessment of discomfort glare. Lighting Research \& Technology 1(4): 235-247.

Einhorn, H.D. 1979. Discomfort glare: a formula to bridge differences. Lighting Research and Technology 11 (2): 90-94. 
CIE.1992. Discomfort Glare in the Interior Lighting, Commission Internatio-nale de l'E'clairage (CIE),Technical committee TC-3.13, Division 4, Interior Environment and Lighting Design, Vienna Austria.

Hopkinson, R. G. 1972. Glare from daylighting in buildings. Applied Ergonomics 3 (4): 206-215.

Chauvel, P., Collins, J.B., Dogniaux R., \& Longmore, J. 1982. Glare from windows: current views of the problem. Lighting Research and Technology 14 (1): 31-46.

Wienold, J., \& Christoffersen, J. 2006. Evaluation methods and development of a new glare prediction model for daylight environments with the use of CCD cameras. Energy and Buildings 38(7): 743-757.

Wienold, J. 2009. Dynamic daylight glare evaluation. Proceedings of Building Simulation. Glasgow,UK, 27-30 July: 944-951.

Reinhart, C.F., \& Walkenhorst,O. 2001.Validation of dynamic RADIANCE-based daylight simulations for a test office with external blinds. Energy and Buildings 33(7): 683-697.

Christoph F. \& Reinhart, C.F. 2002. Effects of interior design on the daylight availability in open plan offices. Proceedings of the ACE3 2002 Summer Study on Energy Efficiency in Buildings, Pacific Grove, USA.

Reinhart, C.F., \& Voss K. 2003. Monitoring manual control of electri Lighting Research and Technology 35(3): 243-258.

Reinhart, C.F. 2004. Lightswitch-2002: a model for manual and automated control of electric lighting and blinds. Solar energy 77(1): 15-28.

Reinhart, C.F., \& Andersen, M.2006. Development and validation of a Radiance model for a translucent panel. Energy and Buildings 38(7): 890-904.

Suk, J. Y., \& Schiler, M. 2012. Investigation of Evalglare software, daylight glare probability and high dynamic range imaging for daylight glare analysis. Lighting Research \& Technology 45(4): 450-463. 
Suk, J. Y., Schiler, M., \& Kensek, K.2017. Investigation of existing discomfort glare indices using human subject study data. Building and Environment 113: 121-130.

Van Den Wymelenberg, K., \& Inanici, M.2016. Evaluating a New Suite of Luminance-Based Design Metrics for Predicting Human Visual Comfort in Offices with Daylight. Leukos 12(3): 113138.

Bullough, J.D. 2009. Spectral sensitivity for extrafoveal discomfort glare. Journal of Modern Optics 56(13): 1518-1522.

Sharma, L., Kishan Lal, K., \& Rakshit, D. 2018. Evaluation of impact of passive design measures with energy saving potential through estimation of shading control for visual comfort (Article). Journal of Building Physics 42(3): 220-238.

Pierson, C., Wienold, J., \& Bodart, M. 2017. Discomfort glare perception in daylighting: influencing factors. Energy Procedia 122: 331-336.

Pierson, C., Wienold, J., \& Bodart, M. 2018. Review of Factors Influencing Discomfort Glare Perception from Daylight. Leukos 14(3): 111-148.

Wang, Q., Lei, L., Lai, J., Tan, J., He, M., Chen, L., \& Zhou, J. 2017. Theory research of glare reduction based on the Fresnel principle. Optik 145: 106-112.

Hall, I. J, Prairie, R. R, Anderson, H. E \& Boes, E.C. 1978. Generation of a typical meteorological year. In: Proceedings of the 1978 annual meeting of the American Section of the International Solar Energy Society: 669-671.

Davies, J. A., \& McKay, D.C. 1989. Evaluation of selected models for estimating solar radiation on horizontal surfaces. Solar Energy 43(3): 153-168.

Zhang Q, Huang J. 2004. Chinese Typical Year Weather Data for Architectural Use. Beijing: China Machine Press. 
Deng, Q.-G., Cao, G.-Y., Liu, Z.-C., Wang, Z.-S., Yang, Y., He, X.-Y.,\& Yu, J.-J. 2016. Annual daylight glare evaluation: Impact of weather file selection. Lighting Research \& Technology 50(3): 446-455.

China Meteorological Bureau. 2005. China Standard Weather Data for Analyzing Building Thermal Conditions, April 2005. Beijing: China Building Industry Publishing House, ISBN 7-112-07273-3 (13228).

National Standarization Technical Committee. 2006. GB/T20148-2006. Spatial Distribution of Daylight - CIE Standard General Sky. Beijing : China Standard Press.

Larose, D.T. 2005. K-Nearest Neighbor algorithm. Discovering Knowledge in Data: An to Data Mining, Second Edition: 149-164. 